\title{
The Birth of a Network: The Brazilian Struggle
}

\section{Janet Frederick}

A national plan for university libraries in Brazil recommends a center for cooperative cataloging, a standard format for computerized cataloging, and development of an online network of libraries. Problems associated with online network implementation in Brazil, such as computer import restrictions, changes in government agencies, and an historical lack of resource sharing, are discussed. The prognosis is positive; the need and motivation are strong.

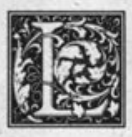

ibrarians in Brazil are seeking to link university libraries via a cooperative cataloging network. During a five-month visit there spent attending a national conference, visiting libraries, and, most importantly, talking to librarians at the forefront of technological change, I learned of the National Plan for University Libraries and of progress toward its implementation. ${ }^{1}$ These librarians described the history of computers in Brazil, library automation development, the politics of change, and the attitudes and ideals of those involved. ${ }^{2}$ Although progress toward building a network continues to be a struggle, expertise and the desire to succeed are evident. Brazil's economic situation is but one hurdle; a new spirit of cooperation will be necessary to ensure better service and further technological advances.

Librarians in Brazil seek technological improvements to upgrade service and bibliographic control and to increase cooperation. In addition, last year the Ministry of Education and Culture approved the creation of a national center for a cooperative cataloging network and the adoption of a standardized format for machine-readable cataloging. In some ways the progress toward a shared cataloging network paral- lels that of the United States; in many other ways the Brazilian experience is quite different. Attaining the lofty goal of linking libraries throughout Brazil through technological means, thereby improving cooperation and resource sharing, will not be easy. Because their country is also engaged in a struggle for more rapid economic development, librarians face an uphill battle. Still, the desire to succeed is strong, and many dedicated individuals are working hard to realize this dream.

\section{THE SETTING}

Brazil is the world's fifth largest country in area and the sixth largest in population (140 million people). The language is Portuguese and Catholicism is the predominant religion. Due to the massive importation of Africans for slave labor and the large influx of European and Japanese immigrants, however, Brazil's cultures and customs are diverse.

Brazil is largely urban. The two largest cities, Rio de Janeiro and São Paulo, have around twelve and fifteen million inhabitants respectively. Brazil is industrializing rapidly; one of the largest industries is automobile manufacturing. Volkswagen do Brasil, for example, exports parts and cars 
to countries throughout the world, including the United States. Brazil's gross national product ranks among the top ten in the world.

In contrast to the modern cities of Brazil with their multinational corporations and sprawling factories, technological advancement has lagged in such areas as the information industry. One reason for slow growth in computerization has been the Informática legislation that brought coordination of research, development, and production of electronic components under government control and established a protected microcomputer market. ${ }^{3}$

\section{COMPUTERS IN BRAZIL}

Computers made their debut in the 1950 s as Brazilian industry modernized rapidly. The first computers, principally IBM and Burroughs mainframes, were imported. By the 1960s Brazilian universities were training engineers in electronics and data processing. Specialists went to the United States or Europe for advanced training and many were frustrated on their return by the absence of a high technology industry in Brazil. According to Peter Evans, "Modernization of Brazilian higher education and of the labor market generated a group of 'frustrated nationalist technicians' with strong personal and ideological interests in the creation of a local computer industry. ${ }^{\prime 4}$

The 1970 s saw advances in the computer area, and from 1969 to 1974 hardware imports increased by 600 percent. ${ }^{5}$ Brazil saw the need to develop its own computer industry, and in 1972 the government created CAPRE, the Commission for the Coordination of Electronic Processing Activities. CAPRE became a "powerful regulatory organ capable of generating an industrial policy for the Brazilian industry. ${ }^{\prime \prime 6}$ After a challenge to Brazil's import restrictions by multinational computer companies, the government saw the need for a more decisive policy if it were to succeed in this highly competitive field.

In 1979, a stronger agency was created: the Special Informatics Secretariat (SEI). SEI became "an aggressive defender of the nationalist line. ${ }^{\prime 7}$ By 1983, local computer companies accounted for almost half the market, and with the advent of the microcomputer, the industry grew even faster. Brazil was able to change its posture from relying on imported computers to importing components and creating domestic products.

The informatics debate continues. The dilemma hinges on the lack of resources to address pressing problems of illiteracy, inadequate housing, and unemployment. Still, the country cannot afford to be without modern technology. As Cavan McCarthy observes, automated information systems "are not only products of industrialised societies, they are also tools which in themselves promote industrialisation. ${ }^{\prime \prime}$ Moreover, Brazilian computers often cost two to three times as much as the U.S. equivalents, and complications abound due to the independent development of systems and software and the lack of standards and guidelines. Victor Rosenberg notes that although the government of a developing country must appear independent of more powerful countries, the truth is that countries are becoming more interdependent in areas of technology. 9 Thus, changes in government agencies, industries, and import laws related to automation and information science have had a negative impact on library automation.

\section{COMPUTERS IN LIBRARIES}

Development of automated library systems has occurred independently, in most cases without guidelines or standards. In some instances institutions automated library functions simply because time was available on the local mainframe. McCarthy's study of library automation in Brazil (conducted between 1980 and 1984) included direct information on thirty-one institutions and indirect data on twelve others that reportedly had automated some functions. ${ }^{10} \mathrm{He}$ found that 40 percent of the institutions surveyed acknowledged having been influenced by another system; another 40 percent developed their systems independently. Import restrictions have certainly interfered with installations of turnkey systems or even widespread use of software programs developed for library operations. However, 
there are other factors that contribute to isolated development of automated library systems.

Thirty-one schools offer bachelor's degrees in library science; five, master's degrees; and one, the University of Brasilia, a doctoral degree. Because of the proliferation of library science programs, most librarians can and do stay in one place throughout their careers. Communication and exchange of ideas between librarians have been difficult in the past. Distances are great between metropolitan areas in Brazil, and there have been few national conferences. Until the present decade, very little knowledge regarding library automation was shared. All this is changing.

In 1980 the Brazilian Institute for Information in Science and Technology (IBICT), the body responsible for assigning ISSNs and publishing the national union catalog of serials, was charged with coordinating library automation activities in the country. In 1981, the Second Seminar on University Libraries included a symposium on automated systems, and in 1984 two national seminars were devoted to library automation.

In early 1987 I visited fifteen libraries throughout Brazil and talked with numerous librarians. I was able to learn of problems with developing and continuing automated library systems. Many of the larger university libraries have automated at least cataloging activities, and special libraries have automated other functions as well. For the most part, only special libraries can afford to use online retrieval systems such as Dialog. Telecommunication capability has only recently been available in Brazil, since the introduction of INTERDATA (international network) in 1982 and RENPAC (domestic network) in 1984.

One of the first (1972) and most impressive systems is that of the Data Processing Center of the Federal Senate, PRODASEN, which includes SCION, the National Congressional Information System. SCION contains a bibliographic database (BIPE, Bibliotecas e Periódicos), an authority file (AUTR) for personal and corporate names, and a controlled vocabulary database (VCBS) as an online thesaurus. The system handles acquisition records, cataloging, circulation, and online public access. As of March 1987, the BIPE database contained more than 100,000 monographic titles and more than 100,000 periodical articles.

Other governmental and specialized bibliographic databases in Brazil include BINAGRE (National Library of Agriculture), BIREME (Regional Medical Library, São Paulo), CAMARA (Federal Chamber of Deputies), CENAGRI (National Center for Documentary Information in Agriculture), CIMEC (Center for Informatics of the Ministry of Education and Culture), CIN (Nuclear Information Center), IPEN (Institute for Energy and Nuclear Research), ELECTROBRAS (Brazilian Electrical Generating Company), and PETROBRAS (Brazilian Petroleum Company).

Two public libraries have automated some activities: the Public Library of São Paulo (using a DOBIS-like system), and the library in São Bernardo do Campo, which developed its own integrated system called TAUBIPE (Total Automation of Public and Special Libraries). ${ }^{11}$

Several university libraries have automated systems for various functions. The Catholic University of Rio de Janeiro has implemented serials control, the University of Brasilia and the University of São Paulo have automated cataloging and acquisitions, and the Catholic University of Pernambuco has online indexing of periodical articles, to name a few. The University of São Paulo's system, SIBI (Integrated System for Libraries), is currently the largest cataloging database in Brazil. Developed in 1981 to handle bibliographic records for $\mathbf{4 2}$ libraries at four campuses, they planned to have over 700,000 monographic titles and 32,000 periodicals entered into the system by June 1987 .

Many librarians in Brazil feel a need for cooperative development of library automation but see it hindered by these independently developed systems, which lack standards. Nice Figueiredo states, "These initial systems in Brazil were isolated, with few possibilities for continuity and were implemented to satisfy local needs only, with restricted performance.",12 A common complaint is that even the li- 
braries of the senate and chamber of deputies, located in the same building, have separate, incompatible systems. Nevertheless, work is progressing toward the development of a framework for an online network for Brazilian libraries, as the following brief history and discussion of plans will show.

\section{SISTEMA BIBLIODATA-CALCO}

In 1972, Alice Principe Barbosa proposed the Brazilian MARC format, called CALCO ("Catalogaçao Legivel por Computador-Machine-Readable Cataloging'), in her master's thesis. ${ }^{13}$ CALCO was based on the Library of Congress MARC II format. Barbosa had been director of the Cataloging Interchange Service (SIC), under the auspices of the Department of Public Service Administration (DASP). SIC was founded in 1942 by Lygia de Queiroz Sambaquy, then director of the Brazilian Institute for Bibliography and Documentation (IBBD), after her visit to the U.S. Library of Congress, where she was impressed with the cooperative cataloging program. Through SIC, libraries in Brazil contributed cataloging data and received free catalog cards. Cards were also made available to other libraries.

From 1972 the CALCO format was studied and revised by the Ministry of Education and Culture at the urging of the National Library. Jannice de Mello Monte-Mor was director of the National Library at that time and, upon her retirement in 1979, further work on the CALCO format was discontinued because the new director had no interest in the project. Around the same time IBBD became IBICT and, due to organizational changes, work on the CALCO format was suspended.

Nevertheless, by 1978 two manuals on the CALCO format were available: one produced by the National Library for bibliographic data input and the other by IBICT for bibliographic data interchange. ${ }^{14}$ In the late 1970s, the Getulio Vargas Foundation (FGV) in Rio de Janeiro began using the CALCO format, contracting with other libraries to computerize their cataloging activities. The National Library joined FGV for computerized cataloging, and thus cooperative cataloging was rein- stituted in Brazil. A shared cataloging database was born, and national standards began to be implemented.

Twenty-seven libraries have since contracted with the FGV for cataloging services and products. Currently libraries enter cataloging onto floppy disks. The disks are sent to FGV, and the libraries receive catalog cards, spine labels, and other items in return. Libraries also receive monthly the BIBLIODATA database (about 160,000 titles) on microfiche for searching prior to cataloging. Future plans include adding music and audiovisual formats, an authority file, and telecommunication access for online searching and cataloging.

\section{THE NATIONAL PLAN}

At the Fifth Seminar for University Libraries held in Porto Alegre in January 1987 , the main topic was the National Plan for University Libraries (PNBu), whose goals included the promotion of "computerization of technical and administrative procedures within university libraries." The objectives listed were

(a) To develop a network for exchanging of bibliographic and documentary data with an extensive data bank ... (b) Maintaining a center which shall supply information concerning library automation .... (c) Encouraging development of suitable software for achieving automation of all library functions; and (d) Supporting adoption of the CALCO interchange format . . . and ensuring compatibility with international standards. ${ }^{15}$

During the previous year, representatives from the major federal university libraries had visited FGV and the University of São Paulo (USP) to look at both cataloging systems. The USP system was considered a viable database due to its size. There had been little quality control in the SIBI database, however, and a great many entries had been duplicated. BIBLIODATA, on the other hand, has maintained extremely high standards of data input, to the point of offering the participating libraries authority work done by the staff at FGV's central library.

At the Porto Alegre conference, a working group of representatives from the university libraries was formed to make rec- 
ommendations to the government regarding implementation of the steps in the national plan. ${ }^{16}$ They recommended that the CALCO format be adopted by university libraries and that FGV be the central network office. By June 1987, a great deal of discussion was underway about coordination, contracts, and costs.

One of the main problems is cooperation. Brazilian librarians are not used to this concept. For example, interlibrary loan is virtually non-existent in Brazil. Murilo da Cunha states that as use of online databases increases so will resource sharing; but currently document delivery is the only measurable type of interlibrary loan that occurs. ${ }^{17}$ With regard to sharing cataloging, some librarians remark that their library will be providing cataloging for other libraries, but that they will find little in the database for their own use. This sort of skepticism is understandable in light of the fact that online shared cataloging is a relatively new concept in Brazil.

Professor da Cunha, director of the University of Brasilia Library and Library School, believes that university libraries in Brazil must join together to achieve their service objectives. According to him, in 1979 there were three million uncataloged books in university libraries; by sharing cataloging via an online network, the processing time and cost will decrease considerably. ${ }^{18}$ Economic necessity often spawns resource sharing, and this is certainly a factor motivating Brazilian librarians as they look toward online networking for help.

\section{BEGINNINGS OF A NETWORK: UNITED STATES/BRAZIL}

Online library networking can be defined as "a group of libraries linked together in a computer and telecommunications system for the purpose of participating in a common system or service." ${ }^{\text {"19 }}$ Certain conditions must exist for networking to succeed. Among the seven listed by Glyn Evans, three exist in Brazil today and a fourth is in development.

Economic pressures and the laborintensive nature of library services, which combine to form one of the conditions necessary for networking, are of prime impor- tance to Brazilian librarians. Budgets are small and cataloging work is extensive. For example, most periodicals are analyzed because indexes are not available. A great deal of detail goes into cataloging activities: AACR2 rules and ISBD standards are rigorously applied; authority work is extensive because Brazilian names are complicated. ${ }^{20}$

The existence of technical standards, such as the MARC formats, is another condition Evans mentions. The CALCO format is operational and is, in fact, being used by 27 or more libraries sharing the BIBLIODATA system. It has also served as a guide for formats developed independently at other institutions. Some revision is still being done, notably the addition of new formats and enhancements for bibliographic interchange. IBICT began development of a standard format for bibliographic and cataloging interchange called "FORMATO IBICT (Intercambio Bibliográfico e Catalográfico)" in 1981 . $^{21}$

Another factor motivating online networking is the societal need for timely information. As a developing country, Brazil requires access to up-to-date sources of data. According to Rosenberg, "The importing of information is critical to national development and [to] the ultimate reduction of dependence on foreign resources.",22

Evans' fourth condition has to do with the development of online computing and telecommunications. As reported above, Brazil's telecommunications network, RENPAC, began in 1984. A consortium of university libraries would be more likely to afford the costs of RENPAC and INTERDATA by using a group contract that offered discounts for increased usage. But exactly how the university libraries plan to interconnect, or how the Getulio Vargas Foundation can link the libraries to their computer, had not been determined by June 1987.

The remaining three items listed by Evans have to do with the volume and variety of published material in the United States and the decrease in computing costs. The publishing industry is small in Brazil, and foreign books are expensive and difficult to acquire. However, periodi- 
cal indexing and other massive data files are needed for access to information. Computing costs, as reported above, are generally higher than in the United States. But the cost of not sharing resources is greater. The conditions outlined above may not be the primary motivations for Brazilian librarians, but they are helping in efforts toward the cooperative development of a network.

At the 1979 Indianapolis Conference on Networks for Networkers, Norman Stevens discussed the fundamental concepts of a network. These concepts can be compared to Evans' conditions. More significantly, however, Stevens pointed out that "the actual developments in the operation of networks ... have shaped the concepts and not the reverse." ${ }^{23}$ The design of Brazil's operational network will not imitate development in another country but, rather, will reflect its own history.

There are about 850 institutions of higher education in Brazil, 22 of which are federal universities. Twenty-seven libraries, including the National Library and two federal universities, were using the BIBLIODATA system by June 1987. If the remaining federal university libraries were to participate, FGV could certainly be considered a national bibliographic utility.

The development of networks in the United States may serve as an example. OCLC went online in 1971, BALLOTS (now RLIN) in 1972, and WLN in 1975. These bibliographic utilities began as networks to serve local needs. OCLC, for example, started at Ohio College Library Center as a statewide network for Ohio. BALLOTS was created to serve Stanford
Libraries and was later acquired by the Research Libraries Group (RLG), and became RLIN (Research Libraries Information Network). WLN, first called Washington Library Network, was designed by Boeing for the Washington State Library. It is now the Western Library Network.

The phenomenal growth of OCLC, from 100,000 database records in 1971 to over five million within fewer than ten years, might serve as an example to Brazilian librarians. Whatever concerns early members of OCLC had about computerized, shared cataloging were quickly dispelled when the benefits of lower costs, faster processing, and access to an enormous national union catalog were realized.

\section{SUMMARY}

The way has been paved. In late 1987, the FGV came under the auspices of the federal Ministry of Education and Culture. This change can improve financial support, but can also encourage cooperation among the federal universities. At the beginning of the present decade, it was noted that "we [the United States] are in the midst of a library revolution as a result of computer-based networking and none of us can predict all of the impacts as change begets change in the evolution of network service. ${ }^{\prime 2}$ Brazil is now in the midst of a similar library revolution. But many of the problems faced by librarians in a developing country are so different from those encountered in the United States that the outcome-the resultant network-will assuredly operate in distinct and perhaps unusual ways to some U.S. eyes.

\section{REFERENCES AND NOTES}

1. This article is a result of a Research Allocation Grant award by the University of New Mexico in 1986-87 to study library automation in Brazil.

2. The librarians interviewed in Brazil are extraordinarily accommodating people. I wish to thank them all for their hospitality. Especially helpful were Jannice Monte-Mor and Lydia Sambaquy of the Getulio Vargas Foundation, Nice Figueiredo of the Federal University of Rio de Janeiro, Murilo Bastos da Cunha of the University of Brasilia, Dinah Poblacion of the University of São Paulo, and Cavan McCarthy of the Catholic University of Pernambuco.

3. Nice Figueiredo, "The Application of Micro-computers in Libraries: A Case Study on Brazil," in The Application of Micro-computers in Information, Documentation and Libraries (Elsevier, North Holland, 1987), p.543-48. 
4. Peter B. Evans, "State, Capital, and the Transformation of Dependence: The Brazilian Computer Case," World Development 14:791-808 (July 1986).

5. Ibid., p.794.

6. Ibid., p.793.

7. Ibid., p.796.

8. Cavan M. McCarthy, "Problems of Library and Information System Automation in Brazil," Journal of Information Science 7:149-58 (Dec. 1983).

9. Victor Rosenberg, "Information Policies of Developing Countries: The Case of Brazil," Journal of the American Society for Information Science 33:203-7 (July 1982).

10. Cavan McCarthy, The Introduction of Automated Library and Information Services in a Newly Industrialised Country: A Case Study of Brazilian Experience (Halifax, Nova Scotia: Dalhousie University, 1986).

11. Janet Frederick, "The Computerization of a Public Library in a Developing Country: São Bernardo do Campo, S.P., Brazil," (submitted for publication, 1987).

12. Figueiredo, "The Application of Micro-computers," p.545.

13. Alice Principe Barbosa, Projecto CALCO: adaptaçao de MARC II para implantaçao de uma central de processamento de catalogaçao cooperativa. (Rio de Janeiro, Master's Thesis, 1972).

14. Sistema BIBLIODATA-CALCO (Rio de Janeiro, Fundaçao Getulio Vargas, 1982); Jannice MonteMor, Unpublished history of Sistema BIBLIODATA-CALCO (Rio de Janeiro, FGV, 1985); McCarthy, Introduction of Automated Library and Information Services, p.154-55.

15. National Plan for University Libraries (PNBu) Directive no. 287 (Brasilia, SESu/BIBL./DOC PLAN/86-001, 1986).

16. Janet Frederick, "University Libraries in Brazil to Share Cataloging," College \& Research Libraries News 48:201-04 (Apr. 1987).

17. Murilo Bastos da Cunha, "Effects of Data Bases on Brazilian Libraries," (Ann Arbor, Michigan, $\mathrm{Ph} . \mathrm{D}$. thesis, Univ. of Michigan, 1982).

18. Murilo Bastos da Cunha, "Rede de dados bibliográficos no Brasil: uma necessidade real," paper presented at the Fifth National Seminar of University Libraries (Jan. 12-14, 1987) Porto Alegre, Rio Grande do Sul, Brazil.

19. Glyn T. Evans, "On-line Library Networking: A Bibliographic Essay," Bulletin of the American Society for Information Science 5:11-14 (June 1979).

20. Brazilians change their names, spell them differently at various times, and names are often a mixture of Portuguese and another nationality.

21. "Formato IBICT," Ciencia da Informaçao 14:175-80 (July/Dec. 1985).

22. Rosenberg, "Information Policies," p.204.

23. Norman D. Stevens, "An Historical Perspective on the Concept of Networks: Some Preliminary Considerations," in Networks for Networkers (New York: Neal-Schuman, 1980), p.45.

24. Barbara Evans Markuson, "Revolution and Evolution: Critical Issues in Library Network Development," in Networks for Networkers (New York: Neal-Schuman, 1980), p.5.

In the past, reading instruction has been limited to the lower elementary grades. But because of the widespread criticism of the inability of college students to read, there are indications that in the years just ahead reading instruction will be part of the instructional program of all schools from first grade through college.

-Mildred Hawksworth Lowell, "Reading and the Training School Library (June 1941), p.229 